\title{
Democracia neoliberal, disciplina y educación de mercado ${ }^{1}$
}

\section{Neoliberal Democracy, Discipline and For-profit Education Democracia neoliberal, disciplina e educação de mercado}

Rodrigo Escobar San Martín²

Recibido: 01/08/2016 · Aceptado: 30/09/2016

\begin{abstract}
Resumen:
La implementación de las competencias en los sistemas educativos globales con su consecuente pérdida de terreno de áreas como la filosofía y las humanidades, trae consigo la concepción de una educación que debe responder a las necesidades de crecimiento y desarrollo económico de los países. El presente artículo analiza de manera aproximativa y crítica la educación neoliberal en Chile, resaltando sus especificidades que la hacen única y a la vez contradictoria. Así también las tensiones y desafíos que el neoliberalismo genera para pensar la democracia y el ejercicio ciudadano.
\end{abstract}

Palabras clave: Educación - mercado - neoliberalismo - desigualdad democracia

\begin{abstract}
:
The implementation of competencies in global education systems with their consequent loss of ground in areas such as philosophy and humanities implies a vision of an education that must respond to the needs of growth and economic development of the countries. This
\end{abstract}

1 El presente trabajo es parte de la ponencia presentada en la XIV versión del Corredor de las ideas del Conosur, celebrado los días 13, 14 y 15 de Julio en la Universidad Católica Nuestra Señora de la Asunción de Paraguay. Asimismo, este trabajo también es parte de la investigación "Formación ciudadana y cultura democrática", adscrito al centro de investigación en fe y cultura de la Facultad de Ciencias Religiosas y Filosofía de la Universidad Católica Silva Henríquez.

2 Chileno, Profesor de Filosofía y Licenciado en Educación por la Universidad Católica Silva Henríquez. Actualmente se desempeña como profesor adjunto en la Universidad Católica Silva Henríquez y en la Universidad de Santiago de Chile. Contacto: rodrigo_escobarsm@hotmail.com 
article analyzes, in an approximate and critical way, the neoliberal education in Chile, highlighting its specificities, which makes it unique and contradictory at the same time. It also analyzes the tensions and challenges that neoliberalism generates in the thinking of democracy and the exercise of citizenship.

Keywords: Education - market - neoliberalism - inequality - democracy.

\section{Resumo:}

A implementação das competências nos sistemas educativos globais com consequente perda de áreas como filosofia e as humanidades, traz consigo a conceição de uma educação que deve responder às necessidades de crescimento e de desenvolvimento económico dos países. O presente artigo analisa geral e criticamente a educação neoliberal no Chile, destacando suas especificidades que o tornam única e ao mesmo tempo contraditória. Assim também, as tensões e desafios que o neoliberalismo gera para pensar a democracia e o exercício da cidadania.

Palavras-chave: Educação - mercado - neoliberalismo - desigualdade democracia.

\section{Introducción. Estado actual de la educación dentro de las políticas educativas globales}

El neoliberalismo y la globalización del siglo XXI no han sido indiferentes a la hora de pensar los fundamentos y fines de las políticas educativas. Un nuevo prisma paradigmático de relación que coloca énfasis en el uso de las tecnologías, los medios de comunicación y las relaciones humanas. Esta nueva estructura semántica que configura una forma de comprensión de mundo y al mismo tiempo una experiencia vital de éste (Cencillo 1970), no solamente ha afectado a las diversas formas de concebir la cultura sino que tiene profundas connotaciones en la dimensión humana (Gevaert 1984).

El año 2015 no ha de ser el mejor recuerdo para la enseñanza de la filosofía y las humanidades, esto porque a nivel global se ha puesto en tela de juicio el servicio que estas disciplinas entregan a la sociedad. Tal y como Heidegger (1994) afirmaba hace bastante tiempo, es el avance imparable del pensamiento calculador: ¿para qué sirven?, ¿cuál es su utilidad? Parece ser las cuestiones fundamentales de las políticas educativas a nivel mundial. Particularmente, lo ocurrido con 
la filosofía en España y la pérdida de su obligatoriedad a manos del gobernante Partido Popular, además de la propuesta de eliminación, matizada por medio de reformas, de las carreras de humanidades en la enseñanza superior que promueve el primer ministro japonés para así fortalecer carreras técnicas que fomenten la reactivación de la economía del país.

En ambos casos, los objetivos centrales de las políticas educativas tienden hacia una imagen de perfeccionamiento de capital humano a través de ciertas áreas profesionales que fomenten el desarrollo de la economía. Por este motivo, una educación más técnica, práctica y ocupacional, solucionaría las necesidades que afectan a la sociedad. El lema que se enaltece es uno solo: a mayor cantidad de trabajadores cualificados en puestos especializados, mayor será el desarrollo y progreso del país. Se promueven especialmente controles de calidad, tanto a nivel institucional como a nivel profesional. Todo esto tiene como fundamento la correspondencia entre la formación de los estudiantes con las demandas del mundo laboral (Tedesco 2007).

\section{Disciplina y mercado en la educación chilena}

Estos hechos noticiosos no han pasado desapercibidos en Chile, puesto que constantemente se han colocado en tela de juicio la obligatoriedad de asignaturas propias de las humanidades. El movimiento estudiantil es un fiel reflejo del descontento general, los estudiantes han levantado la voz y piden cambios estructurales, en un principio al sistema educativo, y hoy al sistema político neoliberal.

Preguntarse por el origen de la crisis que atraviesa el país es navegar por los fundamentos y fines de las políticas educativas que han sido aplicadas en el país.

Las teorías de mercado en la educación, que se arrastran desde la dictadura en Chile, establecieron como consigna luchar contra la ideologización de la educación, promoviendo la libertad individual, la liberalización radical de la economía y la sociedad y la neutralidad en cuestiones políticas (Piñera 1992 77-92). Para ello, la dictadura militar 
ataca y desarticula los centros estudiantiles y los sindicatos que agrupan tanto a docentes y funcionarios de escuelas como de universidades.

Esta fase represiva busca controlar de manera extrema el campo educacional, estableciendo como principio la des-ideologización de las instituciones que la dictadura lleva a cabo como emblema del proceso de guerra en el cual, según el régimen autoritario, se encuentra sumido el país. Lechner (1988) denomina a esta fase de disciplinamiento y represión, "lógica de la guerra". Un ejemplo de ello es una circular de 1974 del Comando de Institutos Militares del Ejército, que busca regular el funcionamiento de los establecimientos educacionales. En esta circular se llama a denunciar a las autoridades militares los siguientes aspectos que ocurran dentro de las clases o actividades educativas: comentarios sobre política contingente, propagación de chistes o cuentos relativos a la gestión de la Junta o de sus miembros, distorsión de los conceptos y valores patrios, propagación de ideas tendientes a disminuir en el cuerpo de profesores, auxiliares y/o administrativos, el concepto de autoridad del director hacia todo su personal (Ruiz Schneider 2010 97-121).

Junto con esta fase represiva se desarrolla un intento de control de las asociaciones de profesores a partir de una matriz corporativista que derivó en la creación del Colegio de Profesores en octubre de 1974 con dirigentes designados a dedo por la dictadura militar. Este hecho en particular tiene hasta hoy un fuerte resabio de lo que es la dictadura en materia educativa, pues el Colegio de profesores sigue siendo el magisterio más importante de la educación en Chile; así también, la celebración del día del profesor cambia su fecha para octubre. Antes de la dictadura militar su celebración era el día 11 de septiembre. Muchos profesores y estudiantes de pedagogía desconocen el origen de la fecha y celebración del día del profesor, día que llama más bien a la reflexión que a una celebración propiamente tal.

Los cambios radicales en política educativas parecen tener dos objetivos principales. En primer lugar, el proyecto neoliberal busca desmantelar el Estado democrático-social con la drástica disminución del gasto fiscal en lo social y específicamente en gasto educativo (Ruiz Schnei- 
der 2010). En segundo lugar, el proceso de privatización del sistema educativo asimila una lógica de entender al profesor como empleado que vende destrezas y habilidades a través de un mercado de bienes y servicios que es exigido por el mundo privado. Como el resto de los trabajadores del país, concebir a los profesores como vendedores de servicios, tiene como finalidad un proceso de disciplinamiento impuesto por una legislación laboral que tiende a suprimir a su más mínima expresión las posibilidades de acción gremial o sindical. Por otra parte, según Ruiz Schneider (Ibid.), el modelo neoliberal apuesta a desincentivar la actividad política de los estudiantes universitarios a través de la implementación de una racionalidad económica costo/beneficio, cuyo elemento basal será el término de la educación superior gratuita.

El principio fundacional de las políticas educativas de la dictadura es la subsidiariedad, como lo plantea Pinochet en una carta enviada al diario el Mercurio en 1979, en que fusiona la racionalidad económica con los fundamentos valóricos de la tradición católica. Así pues, los énfasis que se persiguen son la adquisición de capacidades para ser buenos trabajadores, buenos ciudadanos y buenos patriotas.

El régimen militar plantea que el Estado debe velar por el bien común de la sociedad, cuyas implicancias son fundamentalmente respetar el adecuado cumplimiento de los fines propios de organismos sociales como las familias. Este propósito tiene como consecuencia que el Estado no debe intentar sustituir a la familia, salvo en caso de que ésta se vea imposibilitada de realizar sus fines por su cuenta. En el ámbito educativo, la familia pasa a convertirse en el elemento orgánico de toda la acción educativa, porque es ésta quien define la finalidad de la formación de los niños, o, más bien, la elección del sentido que debe tener esta formación; por esta razón, la función principal del Estado en educación no es otra que la subsidiaria, es decir, la de garantizar a la familia la libertad para elegir las vías y los modos en que pueda realizar esta vocación formativa. A este respecto, Ruiz Schneider dice lo siguiente:

La educación no es una necesidad social, sino que impera una lógica de las preferencias y la libertad de escoger de la familia, en donde se mezclan los temas educacionales católicos del siglo XIX con resonancias friedmanianas. Esta lógica ha reemplazado por completo 
a la tradición laica del Estado docente, basada en la idea de que la educación es un derecho, porque se basa en una necesidad de toda la sociedad, y en la que se procura liberar un espacio de autonomía para la escuela, que no la haga depender completamente de la familia ni de una confesión religiosa o política determinada (2010 106).

El papel que cumple el Estado no es más que el de una institución normativa y supervisora del mercado educativo, perfilando la primacía de la racionalidad económica, tal y como ocurre en los otros ámbitos de la vida social en el país. Los intelectuales más influyentes son economistas como Milton Friedman y Friedrich von Hayek.

\section{Políticas educativas y desigualdad}

Estas políticas económicas convertidas en medidas prácticas para la plena mercantilización de los bienes educacionales son las que básicamente continúan de manera inalterada después de los gobiernos de la transición democrática.

Así concebida la educación, la racionalidad instrumental de corte economicista apela a que la acción estatal sea llevada a cabo en términos de incentivos y no de derechos que poseen las personas para educarse. La dimensión social se desfragmenta en individuos atomizados que tienen comportamientos mecánicamente funcionales a través de sus propios intereses particulares (Taylor 2012), pues no son sujetos que argumenten en común sobre derechos mínimos sociales. Esto es lo que denomina Foucault (2007) el paso del homo economicus sobre el homo legalis.

La redefinición del Estado hecha en dictadura y proyectada actualmente en democracia, ha desplazado la esfera política por la esfera económica, elevando al tecnócrata como personaje político. A partir de los años 90, esta nueva dirección merma la capacidad de incidir en políticas estatales robustas. Sin embargo, el poder estatal aumentará inyectando más recursos y reformas para el control del orden público, tanto en sus ramas policíacas y judiciales (Ruiz 2015). De esta manera, parece ser una ficción la imagen que se tiene a propósito del neolibe- 
ralismo como Estado mínimo, es decir, la reducción de manera importante del rol del Estado en la sociedad, porque parece ser, antes bien, que cambia su sentido social y modo de acción al entregar una mayor distribución económica hacia los distintos estamentos disciplinarios. El sistema neoliberal en educación es propio de un sistema tecnocrático: técnicas e instrumentos; cálculo y utilidad; capital humano y desarrollo económico. Las políticas en materia educativa plantean tecnificar la sociedad gracias a expertos y profesionales altamente capacitados, todo bajo una visión unidimensional de la oferta y la demanda al alero de los procesos de modernización incentivados por el Banco Mundial, la OCDE y el Banco Interamericano de Desarrollo, entre otros.

El sistema subsidiario de la educación mediante incentivos de becas y créditos -voucher-, sumado a la gestión y dirección de corte empresarial-management-, más las prácticas y procedimientos estandarizados a través de evaluaciones por resultados -accountability-, ha propiciado un fuerte control acerca del conocimiento y los valores considerados como estándares medibles y evidenciables. Este tipo de educación que tiende hacia la medición de todo, donde el éxito escolar se vincula al éxito profesional y para ello el rendimiento es evaluado a través de sistemas estandarizados ha generado un fuerte control hacia los profesores.

Lo ideal es que todos los docentes pasen los mismos contenidos, evalúen con los mismos instrumentos y de esta manera los docentes sean evaluados de la misma manera. La calidad de la educación reduce los conocimientos a indicadores y certificaciones que cualifiquen la experticia de la docencia por medio de evidencias y certificados universales, siendo una medida de excelencia los buenos puntajes, vale decir, tener buenos puntajes implica ser un buen profesor. El mercado docente ha generado la aparición de franquicias educativas que compiten entre sí, bajo lógicas del ranking que posicionan a los mejores y peores colegios ${ }^{3}$.

3 El recuerdo del "semáforo SIMCE", iniciativa propuesta hace un par de años atrás por el ejecutivo, buscaba visibilizar los resultados de las escuelas a los apoderados para que tomen las decisiones respectivas acerca de la educación. Esta información de clasificación es eminentemente estandarizada, lo que importa en este caso es la 
Esta manera de concebir la educación por medio del sector mercantilcorporativo da poder de decisión a las familias mediante la esfera económica, en que la libertad individual es concebida en la capacidad que tienen los padres de elegir el colegio al cual los niños pueden asistir, cual si fuere un producto que ha de comprase en el supermercado. Esta educación de supermercado establece que todos tienen acceso de entrada y en consecuencia promovería la igualdad; lo que oculta este tipo de sistema es la profunda fragmentación, diferenciación y segmentación de las desigualdades sociales. Todos podemos entrar al supermercado, pero, una vez adentro, no todos podemos comprar lo que se oferta. En este sentido, el poder adquisitivo nos dirá a qué tipo de educación podemos acceder, reforzando de esta manera las profundas desigualdades que aquejan al país.

Un estudio sobre movilidad en Chile llevado a cabo por el economista Dante Contreras, llega a la siguiente conclusión:

Nacemos de mismo peso y talla, la misma métrica biológica, sin importar nuestros estratos socioeconómicos, en igualdad de condiciones. No obstante, al poco tiempo comienzan las diferencias. A los pocos meses de nacidos los chilenos, tenemos diferencias en nuestro desarrollo psicomotor, el cual revela un temprano despegue de los lactantes de estratos socioeconómicos más altos, lo mismo sucede con los test de vocabulario, aplicados a niños de 2, 3 y 4 años: a los 2 años ya se muestra una brecha significativa entre niños de estratos socioeconómicos altos y los niños de estratos socioeconómicos bajos. Y esta brecha crece en el tiempo, lo que queda ampliamente demostrado en los resultados del SIMCE, revelando claramente que el modelo educacional sigue al modelo de ingreso. Brechas que comienzan en cuarto básico, se mantienen en todo el sistema escolar, se mantienen en el mercado laboral, y eso implica desigual-

universalidad del resultado y no los procesos o problemas que condicionan el contexto escolar. La composición social, el contexto y la comunidad educativa quedan fuera de las consideraciones de medición y datos de la prueba SIMCE. 
dad de ingreso y baja movilidad social, eso no ocurría en el origen, teníamos niños biológicamente iguales en el inicio, pero nuestro sistema educacional y posteriormente nuestro mercado del trabajo, muestran una brecha que no se cierra (2013).

\section{Democracia, tecnocracia y sociedad moderna}

Los efectos de una democracia altamente tecnocrática tienen fuertes repercusiones en la esfera pública y en la formación ciudadana. La multiplicación de los ámbitos de la experiencia humana caracterizados por conocimientos técnicos de tal complejidad y "exclusividad" crean por sí solos una separación entre el espacio de la decisión y el público que es su destinatario natural, que además debería ser su contralor.

Las áreas problemáticas y las prácticas relevantes para la vida pública se convierten en intrínsecamente misteriosas, aunque se trate de temas que no son objeto de una deliberada voluntad de secreto, simplemente por la diferencia insalvable que separa al experto del ignorante o al competente del incompetente (Bobbio 2013). Esto convierte al tecnócrata, en su calidad de depositario 'de conocimientos al que no tiene acceso la masa', en un moderno e involuntario déspota.

Una sociedad ordenada burocráticamente donde el ciudadano se siente poco identificado con ella, más la progresiva pérdida de la participación, denota los graves problemas que tenemos en el país. Taylor (2012) denomina una comunidad parasitaria a aquella donde las personas definen sus objetivos de modo puramente instrumental y conciben de modo puramente instrumental su relación con la sociedad, donde la libertad se reduce a la persecución exclusiva de fines particulares. En el plano político, los votantes serían consumidores que deben ser captados por los partidos políticos.

En tanto que, según Laclau y Mouffe (1987), el ascenso del neoliberalismo expresa el triunfo de un nuevo proyecto hegemónico que busca definir la articulación de los ideales democráticos, como la igualdad de derechos de la soberanía popular y los ideales liberales, 
entregando importancia a la individualidad; en favor de un régimen cuyo único valor absoluto sea la libertad individual concebida como libertad económica.

Asimismo, ante el escenario actual, es difícil que una sociedad con tal nivel de desconfianza entre unos y otros, como la chilena, pueda tener una enseñanza democrática a nivel institucional, pues el respeto y la construcción conjunta de distintos fundamentos morales razonables aparecen como señal de politiquería o demagogia ${ }^{4}$.

La justificación tecnocrática de las decisiones políticas y su vaciamiento ético ha empobrecido el vínculo social y ha diluido la capacidad dialógica como modo de concebir la convivencia en pos de una ética del más fuerte amparada en ideas como el capital humano y el hombre empresa cuya finalidad es la felicidad económica basada en el consumo entregado por el mercado (Biagini y Fernández 2014). Experiencias interculturales como la de los inmigrantes o los pueblos originarios son vistas como alteridades que deben integrarse, es decir, normalizarse desde la perspectiva identitaria dominante, problema que se ha ido arrastrando históricamente en el pensamiento latinoamericano (Salas 2003).

Esta disonancia entre el 'otro' y lo que supuestamente es lo normal, no siempre enriquece la posibilidad de debate, pues muchas veces aumenta la desconfianza, el desprecio, la intolerancia, que no sólo se observa en la escuela, sino en muchos momentos de la vida social.

De esta manera la escuela no sólo se convierte en reproductora de la desigualdad, sino en productora de ella. Así, por ejemplo, al preguntarse sobre cómo la escuela puede superar la segregación en EE. UU., el informe Coleman concluye que la educación no está haciendo nada; mientras que un estudio de Juan Casassus (2014) sobre educación y desigualdad en América Latina, concluye que el factor

4 Las referencias se multiplican constantemente en los medios de comunicación donde una y otra vez "expertos" en materias de diversa índole justifican la apolitización del debate país. En este sentido, la palabra demagogia aparece como sinónimo de calle y sociedad. 
germinal de la desigualdad se encuentra en la escuela. Estos estudios tienen el mérito de demostrar que la orgánica social de un país es una causa importante de la desigualdad en la escuela. Las decisiones políticas en educación visualizan a su vez tanto las fragilidades como fortalezas de la sociedad, que, en el caso de la desigualdad, visibiliza las problemáticas que tiene la sociedad en cuanto a la concepción de educación. De esta manera, hablar de desigualdades de y desde la escuela es proyectar el reflejo de las propias desigualdades que constantemente se impugnan a la sociedad.

En virtud de aquello, son muchos los estudios sobre escuelas efectivas que instalan como consigna la búsqueda constante de resultados, basados en lógicas neoliberales como las competencias, la eficiencia y la innovación, lenguaje que proviene del mundo empresarial ${ }^{5}$. Esto ha repercutido considerablemente en la educación. No es de extrañar la ausencia de formación ciudadana existente en la historia reciente de Chile, que contiene en el fondo un alejamiento y quiebre entre el mundo social y las instituciones políticas. En este contexto, parece primordial considerar las formas de desarrollo que la sociedad chilena ha ido alcanzando en las últimas décadas para pensar la educación.

Pensar hoy en día en la formación de docentes y formación ciudadana implica pensar esencialmente en una propuesta política que asiente sus bases en la democracia. En el plano intelectual, se ha recuperado la importancia que ha tenido la visión republicana, pues en ella el vocablo público tiene una doble importancia que es fundamental a la hora de concebir la democracia: en primer lugar, lo público es la esfera que se contrapone a la privada, esto es, el ámbito en el que se tratan los asuntos públicos, y como acción necesariamente de exposición, de visibilidad en oposición a lo oculto, a lo secreto (Bobbio 2013). En

\footnotetext{
5 A modo de ejemplo se puede citar el informe de la educación superior en Chile de la OCDE (2009). En éste se enfatizan los problemas de forma de la educación chilena, sin embargo, las cuestiones de fondo son las correctas, en otras palabras, Chile tiene buenas políticas en materia educativa, pero mal aplicadas. No es de extrañar que ante este escenario el Banco Mundial promueva el tipo de educación -los fundamentos y fines- que posee la educación chilena, dejando a mera anécdota la forma en que éstas han sido aplicadas.
} 
segundo lugar, la democracia es idealmente el gobierno de un poder que se hace visible, es decir, el gobierno cuyos actos se realizan ante el público y bajo la supervisión de la opinión pública, por lo que existen dos exigencias propias de la democracia que se deben considerar: una de ellas es que los ciudadanos deben ser, sin ninguna exclusión, el pueblo soberano; mientras que la otra es el respeto al principio de representación (Bobbio 2012), la esencia misma de las democracias modernas. Esto implica que debe primar la plena publicidad de los actos de los representantes y su completa visibilidad ante los representados. De manera tal que un gobierno democrático es aquel en que los gobernantes deben ejercer el poder bajo la supervisión de los ciudadanos.

Estos elementos han sido levantados como los grandes supuestos que debe salvaguardar toda democracia, estableciendo la promoción de estos ideales como la garantía que se tiene para poder alcanzar la paz a escala global (Sohr 2008). La defensa de los gobiernos democráticos es también un fenómeno propio de la globalización, este fenómeno plantea la consolidación e integración de los pueblos del mundo.

Una visión optimista de la globalización y de la democracia ha tenido como objeto principal la defensa del consenso y los canales diplomáticos posibilitando que 'el mundo libre' haya triunfado sobre el comunismo y los regímenes autoritarios (Sohr 2008; Mouffe 2009). El resultado que se busca no es otro más que el fin de la guerra. Un mundo sin enemigos en donde los individuos liberados de los vínculos colectivos pueden dedicarse ahora a cultivar una diversidad de estilos de vida, exentos de ataduras y relatos anticuados. Más allá de esta visión que vincula democracia y globalización, se entiende que los supuestos de la democracia se han instalado para quedarse. No obstante, los problemas surgidos en torno a la democracia moderna son precisamente su falta de democratización, es decir, desarrollar condiciones sine qua non para un ejercicio efectivo de ésta.

Esta preocupación la expone el filósofo comunitarista Charles Taylor (2012), que establece una estrecha relación entre la democracia y los ideales liberales mediante dos principios normativos propios de la 
modernidad: la libertad personal y el imperio de la ley. Taylor plantea que estos dos elementos son condiciones de una democracia auténtica, pues estas dos condiciones persiguen que las personas puedan movilizarse con independencia del poder, tanto para cambiar a las autoridades de turno como para determinar las políticas públicas de interés social.

Para ello, la igualdad en derechos ya no puede ser entendida simplemente como igualdad frente a la ley porque sería reducir la totalidad de acciones y significaciones a planos meramente coactivos y de procedimiento. Actualmente pasa más bien por un nuevo momento de significación: el disfrute equitativo por parte de los ciudadanos de algunos derechos fundamentales constitucionalmente consagrados. El camino recorrido desde la igualdad ante la ley, basada principalmente en una igualdad jurídica; hacia una igualdad de derechos amparados por una constitución, cumple en las sociedades modernas un rol fundamental que postula que todos los ciudadanos son iguales, no pudiendo ser discriminados por el sexo, clase social, etnia o religión, porque la constitución apela a los derechos de la totalidad de los ciudadanos, sin privilegios y sin concesiones (Bobbio 2012).

Lo esencial del Estado de derecho parece hallarse en la naturaleza de las relaciones que se establecen entre los miembros de un régimen democrático. Es ahí donde las instituciones toman un rol relevante, ya que los ciudadanos consideran este espacio como propiedad común y de valor inestimable, en el que se esgrime un depósito social importante que dignifica a la sociedad y sus miembros.

A partir de estos supuestos Taylor (2012) expone cuatro condiciones para aspirar a una democracia viable. En primer lugar, una democracia fundada en la soberanía del pueblo requiere que éste sea capaz de una agencia colectiva unificada que construya una cierta identidad de la cual todos los miembros se sientan integrados.

En segundo lugar, la participación de los ciudadanos juega un rol preponderante en la sociedad. Si bien es cierto que el sufragio universal es un triunfo de las democracias modernas, reducir el espacio de participación al voto atenta con los fines de la democracia misma, 
por tanto, la participación de los ciudadanos implica una actividad de decisión y mandato que debe implementarse mediante diversos mecanismos que incidan en el fortalecimiento del autogobierno.

En tercer lugar, los grupos (etnias, religiones, cultura, clases sociales) que conforman el colectivo social deben relacionarse con respeto y sin trabas discriminatorias. El pluralismo y la diversidad debe ser un fenómeno cultural más que normativo, en que prime el sentimiento de igual respeto ante la diferencia como causa de relación y no como fin, en otras palabras, pasar del plano normativo de la tolerancia hacia una ética del reconocimiento (Taylor 1994).

Por último, en el plano económico, Taylor manifiesta que es indispensable reconocer el papel esencial e insustituible que juega el mercado en la organización de la actividad productiva. No obstante, creer necesario que el consentimiento del rol del mercado no significa traspasar el poder a las grandes corporaciones, pues éstas persiguen sus propios fines y beneficios. Por esta razón debe ser contrarrestado por un régimen de propiedad pública (Estado) que instale los parámetros normativos y la dirección política del país.

Sin embargo, Taylor es consciente de que estos ideales han propiciado diversas concepciones de democracia que instrumentalizan uno de los principios rectores de la modernidad, convirtiéndolo en el único mecanismo posible de praxis política para su viabilidad. A este respecto, la libertad individual es tomada por el neoliberalismo transformándola en una racionalidad instrumental con acervo individualista-economicista. En tanto que el imperio de la ley es tomado por regímenes que conciben valores e identidad como la única vía de un relato común que tiende hacia la homogeneidad, anulando cualquier forma de diversidad al construir una mirada totalizante de la realidad. Ambos modelos toman un elemento fundamental situándolo como estandarte de la praxis política, empero lo que oculta este tipo de modelos es que progresivamente se ve necesaria una distancia cada vez mayor de los ideales democráticos.

Como consecuencia de aquello, uno de los grandes problemas sobre la democracia es la dominante tendencia actual de definir a los asun- 
tos comunes en términos puramente individuales en vez de hacer referencia a proyectos comunes que surgen de los ciudadanos. Esta tarea resulta difícil por la creciente pluralidad de identidades étnicas, culturales y nacionales dentro de las democracias contemporáneas. Parece más conveniente enfatizar los derechos individuales y el marco democrático procedimental, en vez de tomar en cuenta los puntos de referencia histórico-culturales y los presupuestos éticos de acuerdo a cómo los ciudadanos definen su rol garante en la sociedad.

De esta manera, el problema de la democracia oscila desde una participación efectiva de los ciudadanos hacia una burocratización del gobierno en que reside su propia eficacia y legitimidad, tendiendo a la progresiva merma de la propia participación ciudadana. Al no existir garantías ni relatos comunes que generen sintonía con la institucionalidad y el accionar del gobierno, hay detrás una exigencia de un gran cúmulo de conocimientos técnicos y de experiencia que debe ser manejado por especialistas altamente capacitados en cuestiones técnicas. La realidad política se convierte de esta manera en un asunto técnico (Esposito 2012).

La participación ciudadana, así concebida, pasa a convertirse en un factor peligroso para un gobierno organizado burocráticamente. La democracia más que una cuestión política parece convertirse en un asunto de especialistas. El individuo reduce su participación política a la exigencia que éste hace al gobierno para que se desempeñe como un instrumento eficaz e imparcial, beneficiando o castigando a las autoridades por medio del voto.

En este sentido la democracia, con fuertes tintes tecnocráticos, se convierte en la herramienta que garantiza los derechos individuales, concibiendo al Estado como un instrumento para los fines privados de los individuos. Este peligro convierte a la democracia -que se define por la existencia de asuntos comunes- en una experiencia de elementos puramente convergentes en donde los ciudadanos participarían de los asuntos comunes siempre y cuando posean algún tipo de interés inherente a ellos. La participación se reduce a una racionalidad costo/ beneficio. 
A raíz de aquello Taylor (2012) propone que el elemento esencial de una democracia republicana es una ciudadanía que se identifique con leyes e instituciones que se valoran como un bien común, fomentando la participación de todos, lo que requiere el reconocimiento de la igualdad de los ciudadanos para poder relacionarse. Por ello, relacionarse plantea manifestar un común aprecio por un universo de distintas opiniones, y por la igual oportunidad de manifestarlas. Este proceso de intercambio construiría, según el autor, una comunidad más humana y diversa.

Por otra parte, también han surgido voces que buscan recuperar los elementos más propios de la experiencia política griega, esto es, la dimensión agonista. Chantal Mouffe (2009) defiende la tesis agonista como elemento constitutivo de lo político. Desde esta mirada, la dimensión agonista admite la imagen del adversario como legítima porque son dos partes en conflicto. Si bien es cierto, la autora admite que no hay posibilidad racional de solución al conflicto, no puede colocarse en tela de juicio la relación conflictual, pues se reconoce la legitimidad de los oponentes. Este aspecto es fundamental: legitimar al otro significa que, aunque la relación sea conflictual, éstos se ven a sí mismos pertenecientes a una misma asociación política, compartiendo un espacio común dentro del cual tiene lugar el conflicto. La interpretación de Mouffe implica ver al adversario, no como antagonista sino como agonista, constituyéndose esta última en la característica esencial para la política democrática. La diferencia entre antagonismo y agonismo implica que este último legitime la política entendida como disenso, donde la multiplicidad de proyectos es posible en un marco institucional consensuado. En contraposición, la pretensión del antagonismo será anular toda diversidad política, esta visión es propia de regímenes absolutistas o dictatoriales, principales fuentes de oposición a la democracia.

Según Rancière (2006), lo esencial de la política es el disenso, siendo éste también el origen de la democracia. Este vínculo paradójico entre política y democracia es concomitante también con el fuerte sentido de co-pertenencia y co-respondencia que tiene el disenso como espacio conflictual sobre la configuración de un mundo común. En esta 
configuración se da la posibilidad de tener-parte en la experiencia del propio espacio social como posibilidad de existencia de un mundo común. La inquietud de esta especificidad como condición de posibilidad precisa interrogar acerca de su sentido, que es por lo demás, la finalidad dinámica del ejercicio democrático. Por lo que el antagonismo de dos bloques que intentan anularse entre sí nada tiene que ver con el ejercicio político de una experiencia democrática.

Finalmente, Esposito (2012) plantea que la democracia moderna comparte íntegramente el destino nihilista al cual se confía nuestra época. La democracia tiene paradójicamente como principal enemigo a sí misma, cuya constante vacuidad gira en torno a diluir, por una parte, toda posibilidad del conflicto a través de la neutralidad y el consenso; mientras que, por otra parte, se postulan como máximas los relativismos morales propios de nuestra época. Esto dificulta construir proyectos y miradas comunes, vaciando a la democracia de contenido y participación. No habría posibilidad de sentido, no habría posibilidad de diálogo. Anular la posibilidad de hablar acerca de asuntos comunes, anular la posibilidad de un 'nosotros' plural, significa dejar a un lado la discusión y la confrontación política acerca de un imaginario social que se autoinstituye y autoconstruye (Castoriadis 2012). Cambiar un ethos democrático por una democracia procedimental es buscar constantemente dispositivos de neutralidad y consenso, teniendo como emblema 'la política de los acuerdos'.

Estos elementos repercuten directamente en la dimensión política, debido a que establecen peligrosamente elementos apolíticos que apelan más a una mirada racionalista universal -totalizante de la realidad-, que a establecer espacios de subjetividades plurales y diversas, que es más propio del sentido de lo que implica ejercer la democracia.

\section{Conclusión}

Michel Foucault (2008) ha señalado los vínculos entre poder y conocimiento, instalando a la educación como un sistema de normalización que legitima este encuentro. Asimismo, Arendt (1996), Adorno 
(1998), Bauman (2008), Bourdieu (1977), entre otros, han mostrado cómo ciertas figuras de poder, adecuaciones, roles y status sociales generan habitus, discursos, procesos de investigación o de validación de información que están relacionados con el poder. Es indudable que para estos autores considerar el conocimiento sobre lo social es un tema profundamente político, por lo que es un espacio de conflicto que tiende a legitimarse y naturalizarse desde una perspectiva hegemónica (Mouffe 2009).

Por este motivo, la educación cumple una doble función: reproduce o transforma los ideales de la sociedad. Por más que se conciba a la educación como el modo que posee el individuo para acceder a formas diversas de pensamiento y modos de vida en una sociedad, se sabe que la educación tiene ciertos procedimientos que distribuyen lo que es permitido dentro de esa variedad y lo que debe ser excluido. Esta doble oposición marca los parámetros normativos que cualquier individuo, inmerso en la escuela como fuera de ella, tiene como posibilidad de movimiento. Foucault (2008) plantea cómo el discurso vincula a la educación y la política como formas de procedimiento, distribución y selección que ordena y jerarquiza tanto saberes y poderes como formas de pensamiento, articulando no solamente la comprensión abstracta sino que al mismo tiempo las prácticas que encarnan rituales de habla y doctrinas que legitiman ciertas categoría sociales de sujeto.

A raíz de aquello, no es raro pensar los vínculos entre educación y mercado que instalan como supuesto educativo fundante la razón pedagógica para el mundo laboral. Frases como: 'a mayor cantidad de trabajadores cualificados en puestos especializados, mayor será el desarrollo y progreso del país' no han de ser extrañas. La promoción de controles de calidad, tanto a nivel institucional como a nivel profesional tienen como fundamento la correspondencia entre la formación de los estudiantes con las demandas del mundo laboral.

¿Acaso es que, en pleno siglo XXI, nos estamos acercando al fin de las humanidades? Esta pregunta ya se la han hecho varios intelectuales. Fernando Savater (1997) acusa uno de los dilemas fundamentales de nuestra época: la desaparición de los planes de estudio de las 
humanidades sustituyéndolos por asignaturas que tienden a reforzar conocimientos técnicos que suponen una utilidad práctica dentro de la sociedad. Por esta razón es que una educación de calidad va de la mano con el perfeccionamiento profesional y su prestigio se manifiesta en el papel que pueden cumplir en el mundo laboral.

Heidegger (1994) expresaba esta inquietud ética que subyace en el espíritu moderno. Gracias a la modernidad el hombre contemporáneo huye ante el pensar porque se encuentra inmerso únicamente en el pensar calculador en desmedro de cualquier otra forma posible de pensamiento. La dimensión antropológica de la modernidad se encuentra en concomitancia con el desarrollo tecno-científico. La importancia del pensar calculador radica en una concepción técnica cuya finalidad se encuentra en lo palpable, en lo medible; lo útil y necesario. Rol que se asigna a funciones específicas de producción para satisfacer necesidades 'reales y tangibles' dentro de las sociedades.

Bajo este supuesto las humanidades nada tienen que hacer, pues sus hallazgos no son evidenciables, no generan utilidad alguna y nada concreto en particular. En la actualidad, ante los escenarios propios de un mundo globalizado se requieren respuestas rápidas y eficaces, por lo que pedir a las humanidades y a las letras dichas respuestas es de suyo inverosímil, ya que no es propio de sus facultades ni de su quehacer. Se necesita gestión inmediata, respuestas inmediatas, por lo que ante las demandas sociales más importantes las humanidades no tendrían nada útil que aportar.

Este tipo de funcionalismo abyecto, en que reina la utilidad, la evidencia y la medición, es propia de la razón instrumental imperante. Dentro de esta visión preguntar cuál es la utilidad y necesidad que tienen las humanidades hoy en día, no es más que preocuparse por un tábano que ronda por ahí y molesta de cuando en cuando. Ante este escenario debe primar la conciencia sobre la importancia que posee la reflexión (si acaso a estas alturas tiene alguna importancia) dentro del sistema educativo.

El problema del neoliberalismo y de sus procesos de significación estandarizada de los contenidos y valores en el ámbito educativo, proyectan 
un profundo acervo sobre las desigualdades, perfiles estandarizados y resultados que giran en torno a la producción del mercado. A partir de esta mirada, tanto las ciencias como las humanidades son elaboradas como instrumentos técnicos, debido a que existe un perfil de habilidades que cada una brinda de manera instrumental a la sociedad. Esto no quiere decir que la ciencia sea técnica, pues posee un rasgo humanizador fundamental.

Democratizar la educación es construir en convivencia una formación más humana, y humanizar la educación es construir una forma de convivencia más democrática (Morin 1999), rebasando la mera asociación instrumental y procedimental.

Por tanto, la educación es central, porque tiene que ver con la autonomía y la convivencia que ésta posibilita. Por esta razón es importante preguntarse por el sentido, no solamente desde una perspectiva instrumental, sino también desde una visión antropológica que rescate las memorias colectivas y populares, vitales para una cultura democrática.

\section{Bibliografía}

Adorno, Theodor. Educación para la emancipación. Madrid: Ediciones Morata, 1998.

Arendt, Hannah. Entre el pasado y el futuro. Barcelona: Ediciones Península, 1996.

Bauman, Zygmunt. Los retos de la educación en la modernidad líquida. Barcelona: Editorial Gedisa, 2008.

Biagini, Hugo, Fernández Peychaux, Diego. El neuroliberalismo y la ética del más fuerte. Buenos Aires: Editorial Octubre, 2014.

Bobbio, Norberto. Democracia y secreto. México D. F.: Editorial Fondo de Cultura Económica, 2013.

Bobbio, Norberto. Liberalismo y democracia. México D. F.: Editorial Fondo de Cultura Económica, 2012.

Bourdieu, Pierre; Passeron, Jean Claude. La reproducción. Elementos para una teoría del sistema de enseñanza. Barcelona: Editorial Laia, 1977.

Casassus, Juan. La escuela y la (des)igualdad. Santiago: Editorial LOM, 2014. 
Castoriadis, Cornelius. La ciudad y las leyes. Buenos Aires: Editorial Fondo de Cultura Económica, 2012.

Cencillo, Luis. Mito, semántica y realidad. Madrid: Biblioteca de Autores Cristianos, 1970.

Contreras, Dante. Desigualdad, movilidad social y educación: la urgencia de una reforma al sistema. Conferencia pronunciada en Santiago, Chile, 2013, octubre.

Esposito, Roberto. Diez pensamientos acerca de la política. Buenos Aires: Editorial Fondo de Cultura Económica, 2012.

Foucault, Michel. El nacimiento de la biopolítica. Buenos Aires: Editorial Fondo de Cultura Económica, 2007.

Foucault, Michel. El orden del discurso. Barcelona: Fabula Tusquets Editores, 2008.

Gevaert, Joseph. El problema del hombre. Introducción a la antropología filosófica. Salamanca: Ediciones Sígueme, 1984.

Heidegger, Martin. Serenidad. Barcelona: Ediciones del Serbal, 1994.

Laclau, Ernesto, Mouffe, Chantal. Hegemonía y estrategia socialista. Hacia una radicalización de la democracia. Madrid: Siglo XXI, 1987.

Lechner, Norbert. Los patios interiores de la democracia. Subjetividad y política. Santiago: FLACSO, 1988.

Morin, Edgard. Los siete saberes necesarios para la educación del futuro. Francia: UNESCO, 1999.

Mouffe, Chantal. En torno a lo político. Buenos Aires: Editorial Fondo de Cultura Económica, 2009.

Piñera, José. "Chile: el poder de una idea". En Levine, Barry (comp). El desafío neoliberal. El fin del tercermundismo en América Latina. Santafé de Bogotá: Editorial Norma, 1992.

Rancière, Jacques. Política, policía, democracia. Santiago: Editorial LOM, 2006.

Ruiz Schneider, Carlos. De la república al mercado. Ideas educacionales y políticas en Chile. Santiago: Editorial LOM, 2010.

Ruiz, Carlos. De nuevo la sociedad. Santiago: Editorial LOM, 2015.

Salas, Ricardo. Ética intercultural. (Re)lecturas del pensamiento latinoamericano. Santiago: Ediciones UCSH, 2003.

Savater, Fernando. El valor de educar. Barcelona: Editorial Ariel, 1997. 
Sohr, Raúl. El mundo y sus guerras. Santiago: Editorial Random House Mondadori, 2008.

Taylor, Charles. La ética de la autenticidad. Barcelona: Editorial Paidós, 1994.

Taylor, Charles. Democracia republicana. Santiago: Editorial LOM, 2012.

Tedesco, Juan Carlos. Educar en la sociedad del conocimiento. Buenos Aires: Editorial Fondo de Cultura Económica, 2007. 